\title{
Vernacular Passive Cooling techniques - A case study of a Vernacular House in Allur Village, Kalaburagi, India
}

\author{
Anju Kumari. J. Wanti ${ }^{1}$ \\ ${ }^{1}$ Dept. Of Architecture \\ PDA College of Engineering \\ Kalaburagi :585102, Karnataka, India.
}

\author{
Vimala Swamy ${ }^{2}$ \\ ${ }^{2}$ Dept. of Architecture \\ REVA University, \\ Bengaluru, India
}

\author{
Sangamesh Sakri ${ }^{3}$ \\ ${ }^{3}$ Dept. Of Electrical and Electronics \\ PDA College of Engineering \\ Kalaburagi :585102, Karnataka, India.
}

\begin{abstract}
In Traditional Architecture buildings were designed by the local builders who are unschooled in the formal architectural design and their works reflects the diversity of local climate, local available materials, tradition and culture of that particular place and most comfortable for all the activities.

Climate had a major effect on the performance of the traditional building architecture and its energy consumption in hot dry area of North Karnataka region. These strategies include: layout orientation, distance between buildings, building orientation \& form, climatic elements such as Roof projections, jharokhas, central courtyard to mention a few
\end{abstract}

Many Vernacular Technologies are Energy efficient and sustainable although some of them are currently no longer functioning properly because of changed culture and ecological situations. In this regard the key challenge is to learn fundamental lessons and principals of Vernacular Architecture, and to find the ways of integrating those principles into development programmes to plan new residence. Studying Traditional Techniques to understand the sustainable strategies used in hot-dry region to achieve thermal comfort should make a valuable contribution to the field. The paper depicts empirical study of a vernacular residence of Kalaburagi.

Keywords - Traditional Architecture, Hot-Dry area, Energy efficient, Traditional techniques, Thermal Comfort.

\section{INTRODUCTION}

Energy is the important component for economic development of the country. The modern equipment and materials used in construction and to maintain indoor thermal environment consumes significant amount of our national energy. In view of the shortage of energy it is very much essential to review the historical origin of Architecture \&Technology to restore the comfort inside the building. Thermal performance and air quality inside the buildings can be improved substantially and energy can be saved through understanding the ancient design concept.

Traditional architecture is the outcome of centuries of optimization of climate consideration, of material use, construction techniques. Ancient buildings demonstrate the passive architecture of that specific region. Without mechanical means these buildings are better than the newly designed buildings. Natural ventilation and advantages of solar direction was taken in those buildings. Materials are chosen for construction according to the climatic characteristics of the place. Vernacular Architecture of HotDry places like The Palaces in Rajasthan also demonstrates the natural ventilation techniques. Havelis of Rajasthan and Gujarat are good examples of passive architecture (Gupta, $N$. / Journal of Buildings and Sustainability, 2017, Vol. 2, No. 1). Courtyard was also an important design element in old residential buildings in hot dry climate called Havelis. It was an element of passive cooling for regular fresh air supply.

The vernacular architecture is constructed by indigenous people without any knowledge about architecture which is a more functional design rather than an aesthetic design for satisfying the initial needs and protections from wind, rain and harsh climatic situations.

\section{PURPOSE OF STUDY:}

The fundamental purpose of buildings is to provide man with a comfortable working and living space, protected from the extremes of climate. In these days of fuel crisis, it is important that such comforts be provided with as little expenditure of energy as possible. Vernacular architecture with hundreds of years of experience behind it has evolved appropriate building methods for each type of climate.

\section{DESIGN PROCESS IN KALABURAGI:}

Decisions to be made during the design process in hot dry climate include: -

- Planning Decisions

- Functional Decisions

- Material Related Decision

PLANNING DECISIONS:

\section{House Plans:}

- Compact Plans are preferred as these will expose minimum surface to harsh solar radiations.

- Deeper rooms are better against hot outside solar radiations.

- Inward looking plans best suits for this type of climate as these straight away protect us from external solar heat and radiation. 


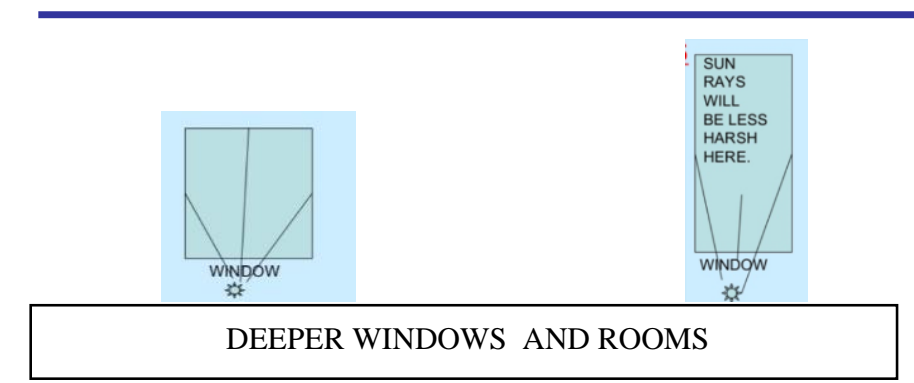

- $\quad$ Courtyard planning along with some trees and small water body creates very good cool microclimate as evaporative cooling effects occurs in this type of courtyard.

- Thicker external walls with the minimum windows should be used to avoid heat and solar radiations.

- Heat producing areas should be separated from other areas of house.

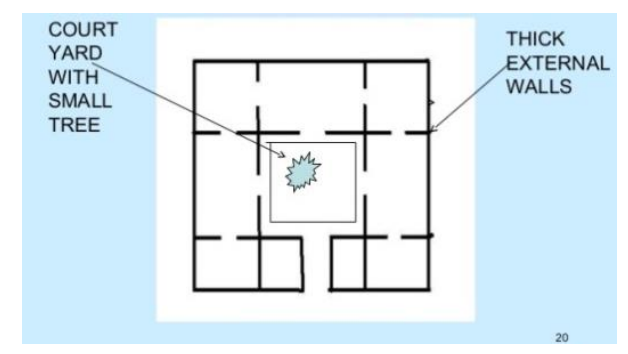

Fig.1 Court Yard Concept with Thicker Walls

\section{FUNCTIONAL DECISIONS: (OPENINGS)}

- Physical Access

- Fresh Air inlet.

- Used (hot) air outlet.

- Light

- Visual Access

- Audial Access
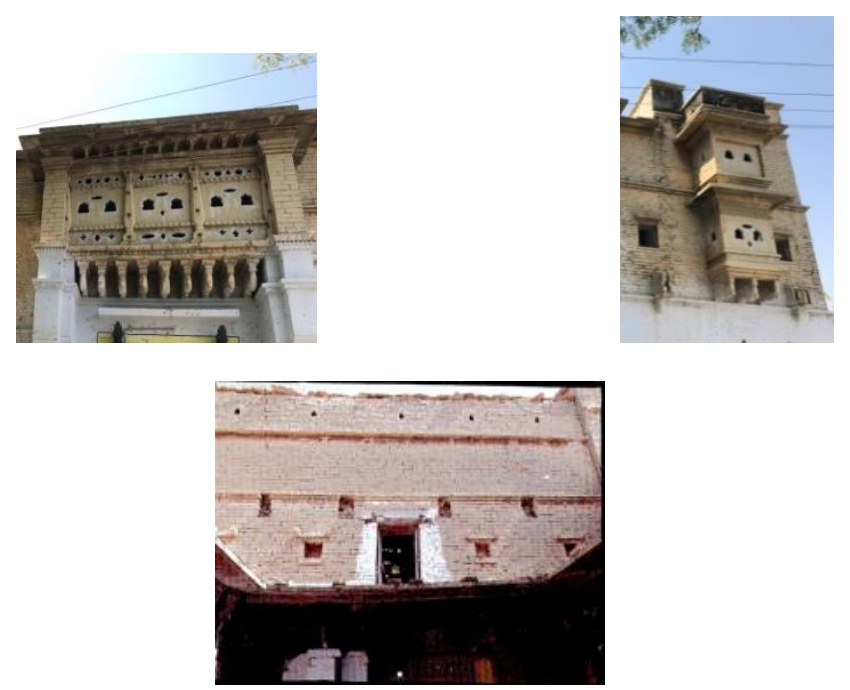

Fig2.Small Openings Provided for Ventilation and Visual Access

\section{MATERIAL RELATED DECISIONS:}

Material and Construction Technique is vital in setting forth the chemistry of building with external elements through its thermal coefficient, material properties and dynamics of its physics. If sunburnt clay block is taken as a unit of energy demand of material, cement is nearly 10 times energy intensive, steel is 30 times and aluminium 160 times.

Finishes and Surface Articulation: Although Seemingly micro, the skin rendering turn out to be the first aspects of building to negotiate with environmental conditions. As the first soldier, it takes most of the burns of nature.
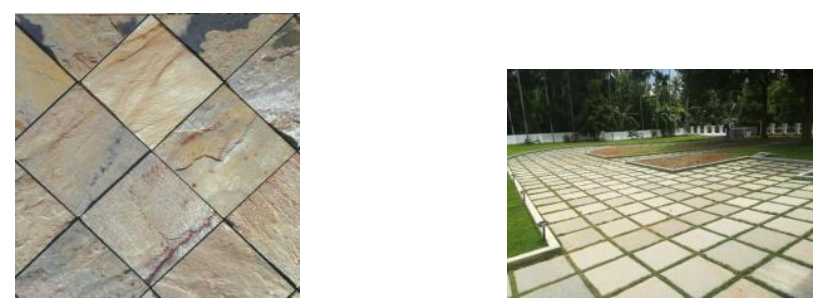

Fig3. Shahabad Stone Used for Indoor and Outdoor Flooring

Shahabad Stone is one of the wonders of Mother Nature. Slabs stacked neatly say it all. And it's just below the top soil, not much effort required to haul them out. Here's one of the quarries while travelling between Chitapur and Shahabad.
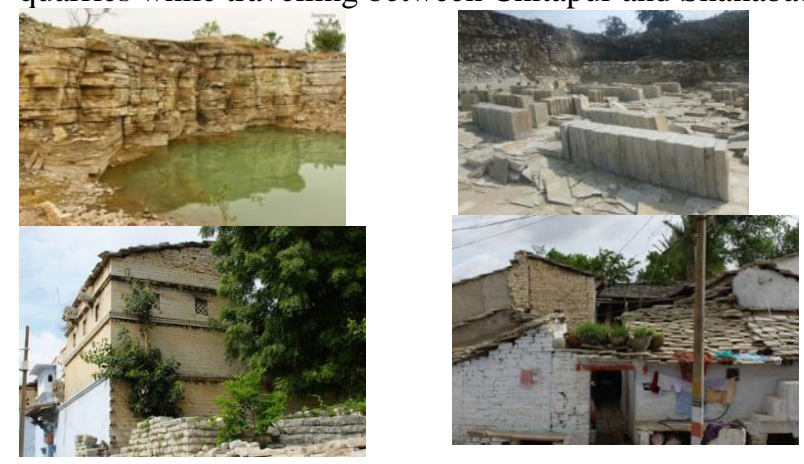

A multi-storey house and a smaller house which is totally constructed using Shahabad stones from foundation to roof.

There is nothing that binds these stones together. If we closely observe we find they are placed skilfully one above the other. The use of local materials, local technology for construction of buildings with the help of local artisans helps vernacular buildings energy efficient. The most wide spread building materials are sand stone, Basalt (Deccan trap) stone, schist, granite (pink or grey colour), lime, shale, timber, mud, Shahabad stone, etc.

Massive Walls
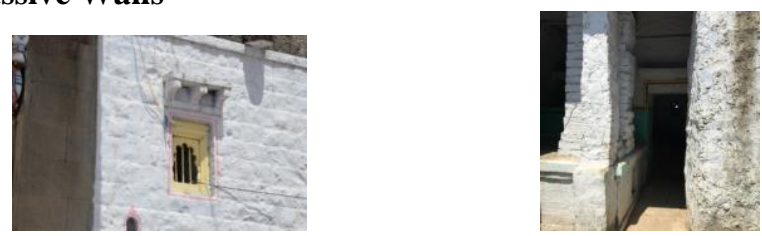

The walls of vernacular buildings are massive with the thickness varying from $45 \mathrm{~cm}$ to $60 \mathrm{~cm}$. The thick walls are 
constructed with Shahabad lime stones and mortar of lime and surkhi, the walls are sometime pointed or remained unfinished without plaster, thick walls stores large amount of heat due to large heat capacities and create a larger timeline, this helps the inside cool during day time when it is most inconvenient outside, on the other hand in winter heating requirements are reduced due to heat stored in the walls which is radiated during night.

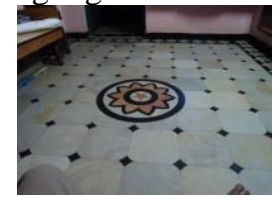

Fig4.Polished Shahabad stone flooring

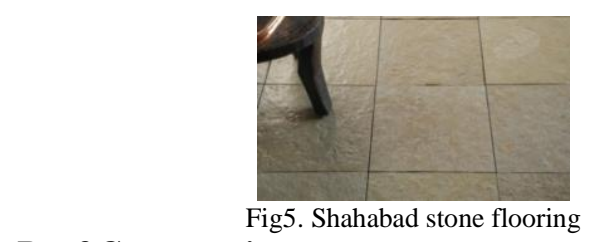

Roof Construction

Fig5. Shahabad stone flooring

- Sloped roof

- Pitched roof

- Brick bat slab

- Flat stone slab roof

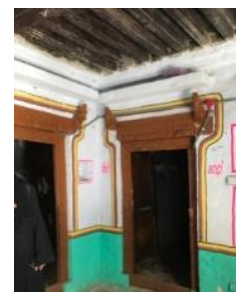

Fig6.Timber Beams

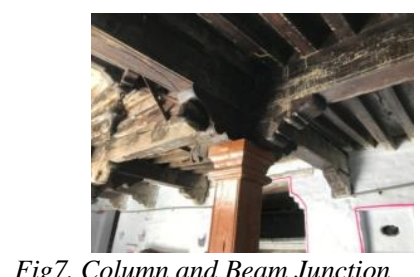

Fig7. Column and Beam Junction
The massive roof construction of thickness $(15$ to $30 \mathrm{~cm})$ ensures a very large time lag for sun radiations to penetrate the interiors.
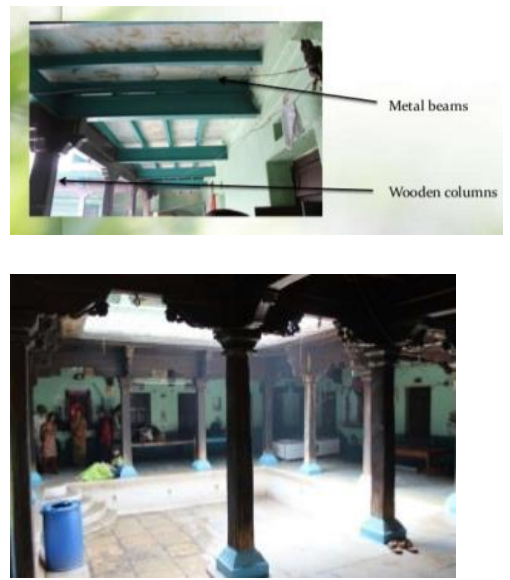

Fig8. Roof with A Wooden Column and A Metal Beam and Wooden Columns and Wooden Beams.

Roofs were constructed with the help of wooden logs and Shahabad stones for the covering. Metal 'I' sections were used as an alternate material to support roofs and lime mortar as weathering coat.

\section{CONSTRUCTION TECHNOLOGY:}

- Foundations are built out of stone with lime mortar.

- Walls (1'6" to 3'6" thick) are built out of finely cut or rough tooled sand stone, basalt stone or Shahabad stone with lime mortar.

- Roofs are covered with stone slabs supported by wooden beams \& rafters in the natural form topped by lime mortar. In some places stone slabs supported by wooden beams \& joists cut into required size \& it is topped by lime concrete $\&$ finished with lime mortar.

- The paving of entrance lobby \& court is generally in the rough stone slabs set either regularly or random rubble fashion. Floors of veranda \& rooms are of stone slabs.

SHADING DEVICES: The natural cooling may be achieved by cutting off the sun's radiations, reducing the absorption and slowing down the transmission of heat. The sunshades not only protect from sun's radiations through the windows but walls too. Vernacular buildings have deep and inclined sun shades which are more effective as they cover the more surface area. Deep carving on building exteriors causes mutual shading in the day and in the evening and the extended surface area increases convective heat transfer to the air.

Tapered windows with smaller section inside also increase the velocity of entering air. The hot air rises up in a domed space and the vents near the ceiling allow hot air to escape.
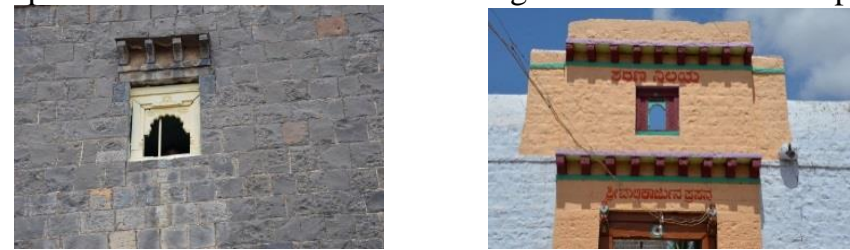

Fig9.Very Small Window Opening Seen On The Huge Walls

A small window on a huge wall, as we see in most of the buildings in hot dry \& composite allows the wind to move inside the building with a greater force (Gupta 1984). When the air with a greater velocity enters into a wider space, sudden expansion results in lowering down of the temperature of inside spaces of the buildings.

\section{LATTICE SCREEN:}
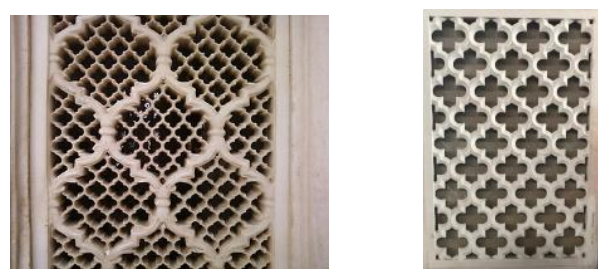

Fig10. Jaali Work Providing Privacy And Internal Cool Spaces

Another strong feature which makes the internal spaces cool is lattice screen or jaali. Jaali is used frequently in buildings of composite \& hot dry region architecture and is a prominent element. On one hand, it provides privacy and it controls the airflow and lower down the temperature of 
internal spaces on the other. When there is sunshine outside in the day, the internal spaces are not clearly visible from outside however, the diffused light is spread throughout the interiors. To get a clear outside view, a cutout is provided at eye level for the viewer sitting on the floor.

\section{CULTURAL ASPECTS:}

The way of life of building occupants \& the way they use their shelters, is of great influence on building forms. The size of family units, who shares which spaces, how food is prepared \& eaten, how people interact and many other cultural considerations will affect the layout \& size of dwellings.

Culture also has a great influence on the appearance of vernacular buildings, as occupants often decorate buildings in accordance with local customs and beliefs.

\section{MICROCLIMATE CONTROL:}

The environment outside the building is important to control the inside temperature of the building. The external air is treated by improving microclimate of the region which consequently enhances the quality of air inside the building.

Vegetation \& water bodies were added to improve the quality of outer spaces and to enhance cooling by evapotranspiration. Planting deciduous trees to shade east and west walls would prove beneficial in hot and dry zones. In summer, they provide shade from intense morning and evening sun, reduce glare, as well as cut off hot breezes. On the other hand, deciduous trees shed their leaves in winter and allow solar radiation to heat the building.

\section{INTEGRATING INDOOR OUTDOOR LIVING:}

The relationship between human activities and nature was strong in the past. With the passage of time, this harmony was weakened resulting in buildings designed without context. With minor inconvenience, the users were suggested to shift from less comfortable spaces to more comfortable spaces depending upon the seasonal changes. Whenever it was uncomfortable inside the buildings, the people were suggested to use the outside spaces.

Even today, people in villages spend their daytime on lower floors while they spend their nights on the terraces. The roof tops become the centre of activities on sunny days in winters.

\section{CASE STUDY:}

In order to see the practical use of above listed parameters in providing natural cooling in hot-dry climate regions, a residential building of Allur village Chitapur Taluka in Kalaburagi city of Karnataka State in India have been considered. Description of house is given below:

\section{ABOUT THE VILLAGE ALLUR : LOCATION :}

Chittapur is located at $1712 * \mathrm{~N} 77.08 * \mathrm{E}$ it has an average elevation of $403 \mathrm{mts}$. The town is spread at an area of $35 \mathrm{~km}$. chittapur taluk has borders only with other talukas of
Kalaburagi district . It borders Kalaburagi to north west chincholi taluk to north, sedam taluk to the east, yadgir taluk to south east, shahpur taluk to the south and jewargi to the west. Kanga river flows in this taluk.

Allur is a small village/hamlet in Chitapur Taluka of Kalaburagi District of Karnataka state. It comes under Chitapur Taluka panchayath, Kalaburagi division. The village is $18 \mathrm{kms}$ away from Chitapur Taluka. It has its own historic background. There are ancient ruined temples and mosques scattered in this area which probably belonged to the Rashtrakutas.

\section{ACCESS TO ALLUR :}

The village comes under Chitapur Taluka. It is located $34 \mathrm{kms}$ from district headquarters and $51 \mathrm{kms}$ from state capital, Bangalore. By Road: chittapur is nearest town to allur road connectivity s there from chittapur to allur.

\section{POPULATION:}

According to 2017 census, presently the village population is 5635 out of which 2763 are female and 2872 are male. Total households are 1200. Literacy rate of this village is $48.76 \%$.

\section{CLIMATE:}

Climate in this area is Hot dry climate and the village is too hot during summers. The highest day degree temperature during summers is around $34 * \mathrm{C}-42 * \mathrm{C}$. Average temperature in January is $27^{*} \mathrm{C}$ and $29 * \mathrm{C}$ in February. According to 2017 weather survey reports, the average rainfall was $410 \mathrm{~mm}$ per year, the maximum wind speed was $20 \mathrm{mph}$. the average humidity was $56 \%$ and average pressure was $1009 \mathrm{mb}$.

\section{ARCHITECTURE:}

Buildings in this village are usually constructed by stone in Islamic Architecture or Chalukyan Architecture by Rashtrakutas.

One of the most significant influence on vernacular arcitecture is the micro climate of the area in which the building is constructed. Buildings in warm climate , in contrast, tend to be constructed of lighter materials and to allow significant cross - ventialation through openings in the fabric of the building.

\section{ABOUT THE HOUSE:}

Life Style: Life style of an area is determined by the activities performed by the people $\&$ the activities performed in context to housing. A rural house has to incorporate a large multitude of activities within it. The activities inside \& those in the surroundings of a house, shows the life of a villager \& his family members as a daily routine. The people use different spaces in the house for fulfilling their activities.

The aim of vernacular architecture was catered to large families to live under one roof \& enjoy the commonly owned facilities of the homestead. 
$>$ The house is located behind Angal Basveshwara temple. The main door facing towards East.

$>$ This is one of the well-preserved houses of Allur.
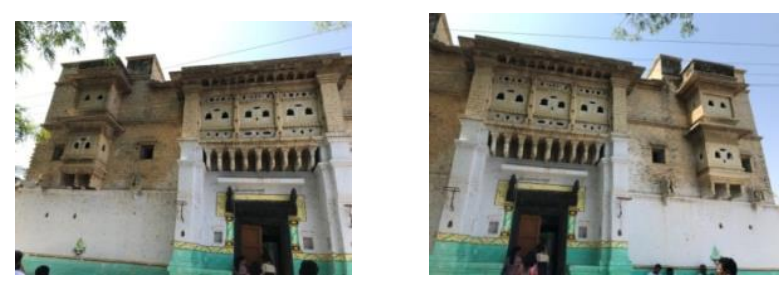

Fig11. Entrance Façade of the House

$>$ The façade is usually symmetrical around a central projection. The tallest and most impressive feature of the house.

$>$ There is a huge front façade made of stone and a little of wood, it acts as an entrance to the house.

$>$ There are two doors in the entrance one for the main entry to the house, and the other door is for the entry of the cows.

$>$ As we proceed towards inside, there is a central courtyard which is open to sky and as a teak wood pillars on all side.

In hot dry and hot humid climates, courtyard is the centre of the building provides a comfortable place for living. The courtyard makes a plan internally oriented and prevents the internal spaces from solar radiations and hot-and-dusty winds. It always shaded throughout the day even if the building is oriented to any direction. In the evening, air temperature falls considerably due to reradiation to the night sky.

$>$ Around this courtyard we find a mezzanine floor on the either side. At one side it is used for storing of grains and fodders for the cattles and on the either side it is used for sleeping. Central courtyard has a sloping stone roof to face the onslaught of the torrential monsoon.

$>$ A narrow corridor runs all around the courtyard connecting to the room in the upper floor.

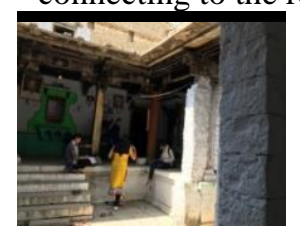

Fig12. Courtyard

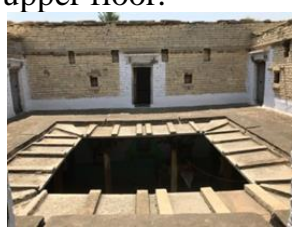

Fig13 Open to Sky
$>$ It has an open roof space in the middle, so that the rain water is collected within and excess water is drained out

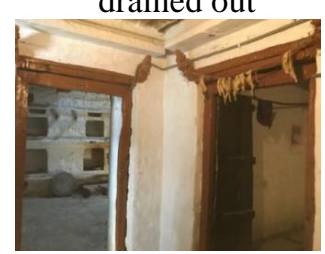

Fig14. Kitchen

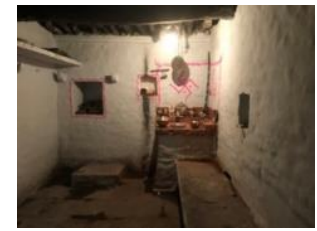

Fig15.Puja Room
$>$ Both the families share separate kitchen, separate puja room separate bedroom, and one common hall, the rooms are symmetrically divided from the padasala.

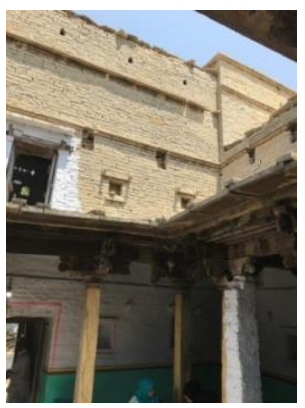

Fig16. View Of First Floor

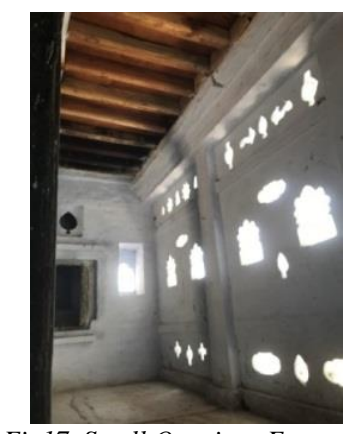

Fig17. Small Openings For Light And Ventilation
$>$ In the upper floor there are eight rooms which consist of two halls and six rooms which are used mainly for sleeping and storing grains, and drying grains.

$>$ Light and ventilation is obtained through small windows and openings.

$>$ The house is made primarily of stone.

$>$ The principle building material is stone and wood.

$>$ The house is totally made using locally available materials accessible around area to suit the climatic and traditions of the owner.
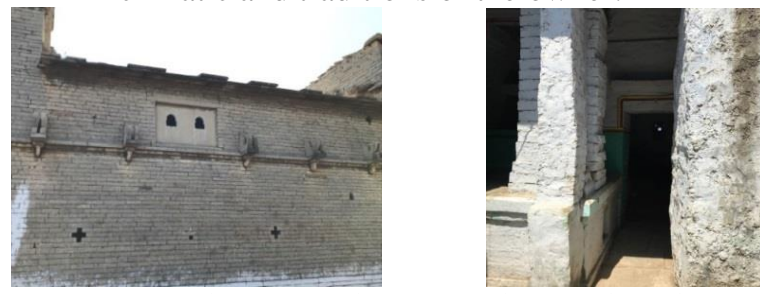

Fig18. One of the common characters is the use of lime plaster on the walls.

$>$ The lime plaster is used to help to keep the insects' away and also reflected sunlight to reduce the heat within the house.

$>$ The roof of the house is also covered with flat stones, slabs, packed with mud.

$>$ The wooden pillars support the roof.

$>$ The kitchen is at the rear of the house or even a little away to keep the smoke away.

$>$ There was a separate toilet area for ladies which are placed at the rear side of the house.

$>$ The unique feature of that house is that men and women share kind of respect, status and position.

$>$ The whole façade is constructed using Shahabad stone.

$>$ Small windows are provided so that hot air should not enter the building.

The design criteria in this Hot Dry region are to resist heat gain \& promote heat loss \& increase thermal capacity because of high temperature, low humidity, hot winds \& clear sky with high solar radiation. 
PASSIVE COOLING TECHNIQUES OF THE RESIDENCE:

The Planning Concept:

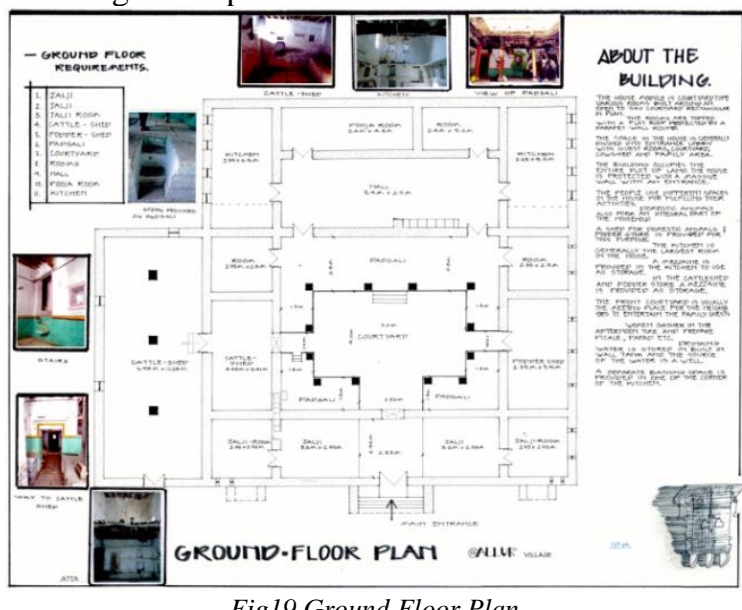

It is 150 years old two-storied building. Plan of the building is simple, square and symmetrical about NorthSouth axis. The building is functionally convenient. The main entrance is from the Eastern side. The first entry leads to Jhalaji and goes to the open courtyard. Then it goes to main building. The plan of the building is compact. All rooms are arranged around central courtyard. Doors of all the rooms are opened to the central courtyard. On the left side they have cattle shed which has a separate entry beside the main door and on the right side there is a fodder store room for the cattles which has a mezzanine floor used for storage purpose.

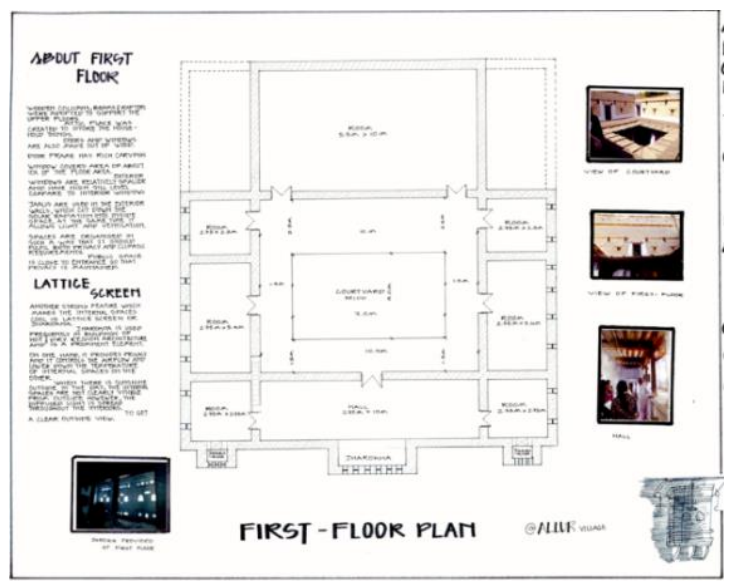

Fig20.First Floor Plan

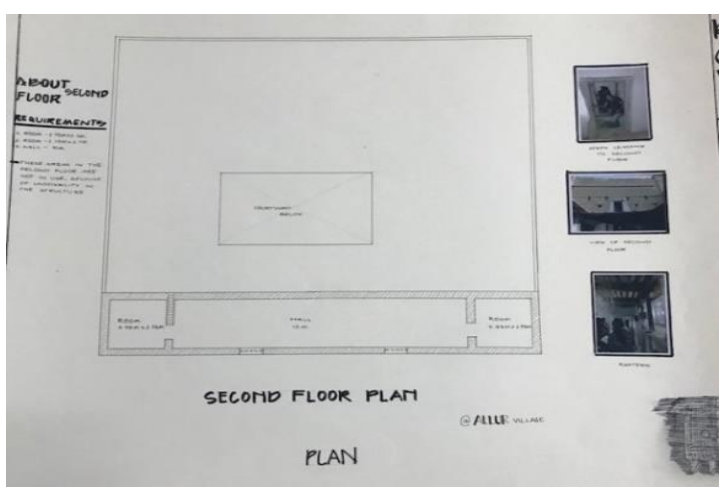

Fig21.Second Floor Plan
In the first floor again, rooms were surrounded on all the four sides. Window openings were very small. Windows had a high sill level and windows were covered with the jali works from outside. Another strong feature which makes the internal space cool is the lattice girder or jharokha. It is a prominent element of vernacular architecture of hot dry climate.

On one hand jharokha provides privacy and it controls the airflow and lower down the temperature of internal spaces on the other, when there is sunshine outside during the day time the internal spaces are not clearly visible from outside. However, a diffused light is spread throughout the interiors. To get a clear outside view, a cut out is provided at eye level for the viewer sitting on the floor.

In the third floor the western side is fully covered with the rooms. This creates a shadow in the courtyard from the west side in the hot afternoons during summer thus creating natural cooling effects to the rooms below where maximum activities take place.

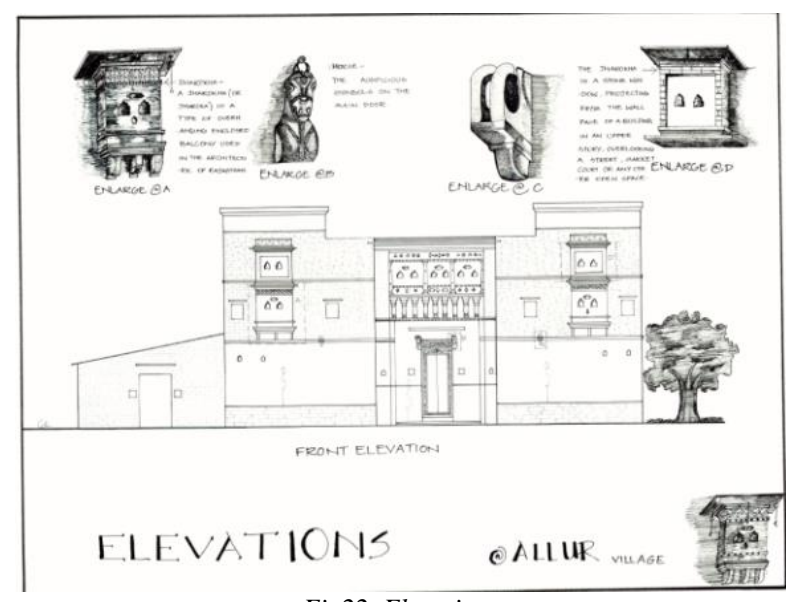

Fig22. Elevations

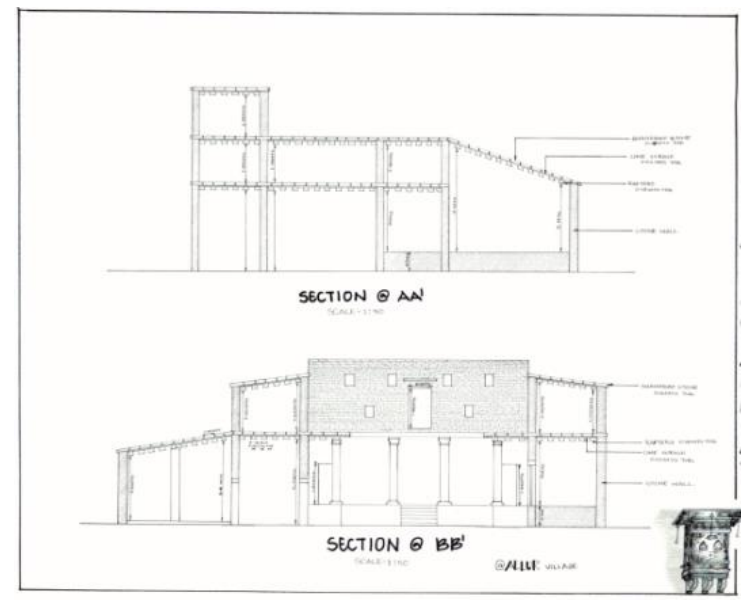

Fig23. Section 


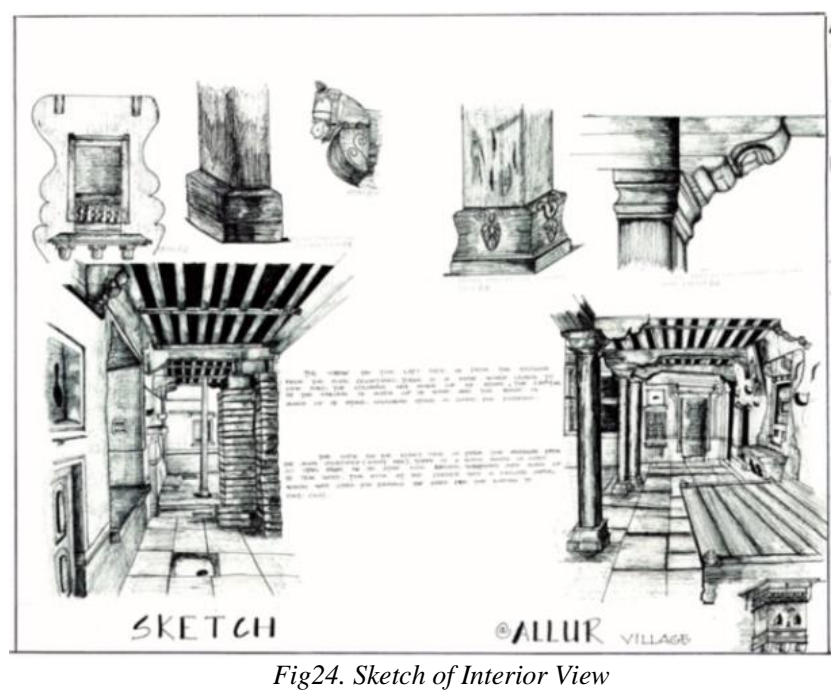

External walls are $900 \mathrm{~mm}$ thick and internal walls $450 \mathrm{~mm}$. Materials used for the construction of walls are stone, mud and lime mortar. The time-lag factor of external walls is more than 12 hours. So it absorbs the heat during day time and release at night. Thus, it maintains daytime comfort, but at night hours some discomfort is felt during summer because of small ventilation. Small openings are provided to get required ventilation and to stop solar radiation, glare and dust. Roof is made with well-compacted lime surkhi on which Shahabad stones are laid. The roof is supported by the wooden columns and rafters on which lime surkhi is compacted.

The buildings function according to seasonal changes. In summer, one feels cool and comfort inside during daytime. Courtyard and roof top are used for sleeping as the rooms remain hot at night due to small ventilation. During winter, the heat stored in walls during daytime radiate at nights in the rooms and provides the comfort without using mechanical system. But throughout the year the building is comfortable without using artificial systems of cooling.

At close sight, the textures of the walls and roofs in rural houses express the earthiness and simplicity of rural lifestyles. The rural craftsman is in total control, producing a variety of textures. In areas which abound in stone, the roughhewn stone in mud mortar with natural colours, covering a wide range, is generally left completely exposed. These wall textures have a kind of perennial beauty in spite of the coarse finish. Where mud mortar and whitewash are used, one finds a reposeful smoothness and whiteness which contrast with the natural strong colours of the roofing.

The study of the vernacular architecture principles is not just to copy them in the present context but to have a better understanding of the environment, life style, tradition and culture of the society and their influence on the built forms of the vernacular residences have evolved in response to the climate, life style and availability of the materials and techniques specific to that region which ultimately lead to sustainability. The vernacular dwellings strongly express that more than quantity of spaces such as variety and size it is the quality of spaces with most efficient use that matters. Spatial flexibility and the climate conscious design approach have been adopted in these structures which enhances the qualitative aspects of each and individual space. The desirable thermal comfort conditions are achieved in these houses with no or minimum use of mechanical devices. Thermal comfort is all achieved mainly due to its planning aspects in terms of its plan, elevation, sections, form and other architectural details of the structure. The materials used and the techniques adopted may be expensive and time consuming in the present condition but the context and relevance of these aspects in satisfying the users need is highly appreciable and the essence of these need to be explored in modern context.

\section{CONCLUDING REMARKS :}

From the case study of the above residence following are the conclusions:

(i) The energy consumed in the residences for the thermal comfort can be reduced by the climatic consideration of that region and by using a better degree of natural conditions.

(ii) The most important factor is the relation between the interior and exterior environment, building form, orientation and the materials used for the construction.

(iii) Considering the sun path and the wind direction create the natural comfort in the building.

(iv) In hot dry climate the building orientation should always be north-south i.e. longer sides of the rectangle should be facing along north and south.

(v) Landscape can also be a passive cooling technique which controls wind, solar radiation and extreme temperature.

(vi) Along with the wind direction if a buffer space or a water body is provided then the intensity of heat is reduced until it reaches inside. All the service areas like toilets, stairs, and stores can be provided on western sides so that the other habitable rooms are cool.

(vii) Courtyard is the important feature of the vernacular architecture. All the rooms of the house will be surrounded all around this rectangular opening which act as a source for natural light and ventilation and provide shaded spaces.

(viii) Thicker walls act as a cooling technique as the intensity of heat reduces by the time it enters inside thus providing a comfortable indoors.

(ix) The window sizes are small and the window sill is also high thus reducing the heat gain and increase the light penetration. The ventilators are also provide very high thus it helps in removing the hot air from inside.

This paper has reviewed the passive techniques applied In Kalaburagi to achieve thermal comfort. These vernacular houses had been constructed with some underlying principles conveyed from one generation to other, to make it respond positively to the prevailing climatic condition. The vernacular housing has efficiently been 
withstanding harsh climate for so many years. The indigenous principles are decoded and can be applied to any residences in the hot and dry area. Understanding the potential of passive techniques will greatly help in reducing the dependencies on energy for achieving thermal comfort.

\section{REFERENCES}

[1] Ashwani Kumar and Navneet Munoth, (July 2011) Vernacular Architecture -A pre-requisite for Sustainable development Architecture Time Space and People: Council of Architecture India.

[2] Al-Ajmi, F, Loveday, DL \& Hanby, VI 2006, 'The cooling potential of earth-air heat exchangers for domestic buildings in a desert climate'. Building and Environment, Kuwait.

[3] Amer, EH 2006, 'Passive options for solar cooling of buildings in arid areas.' Energy, Iran.

[4] Bansal, NK, Hauser, G \& Minke, G 1994. Passive building designA handbook of natural climate control, Elsevier Science, Amsterdam.

[5] Cowan, H.J. (1980) Predictive Methods for the Energy Conserving Design of Buildings. Applied Science, London,

[6] Gupta, V. (1992) Energy conservation - Indian myths and realities. Architecture Design India.

[7] Krishna, A., (2000) Climate Responsive Architecture-A Design Handbook for Energy Efficient Buildings. Tata McGraw-Hill Pub. Co. Ltd., New Delhi.

[8] Rai, G.S. (, May-June 1992) the listing of heritage. Architecture Design, India.

[9] Rai, S., Attuned (April 1991.) climate sensitive design and energy efficient Buildings. Indian Architects and Builders, India.

[10] Sharma, M.R. (1969) Orientation of buildings. Building Digest, No. 74, CBRI, Roorkee, India. 